the unhydrolyzed sawdust, except in one or two cases where the filtration was slow, owing to the porosity of the crucible. The results in Table $V$ were obtained using the original untreated sawdust.

\begin{tabular}{|c|c|c|c|}
\hline Cellulose Sample Obtained from & $\alpha$-Cellulose & B-Cellulose & $\gamma$-Cellulose \\
\hline 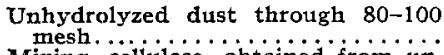 & 57.36 & 19.61 & 23.03 \\
\hline $\begin{array}{l}\text { Mixing cellulose obtained from un- } \\
\text { hydrolyzed sawdust, } 80-100 \text { mesh, } \\
\text { and unhydrolyzed sawdust through } \\
100-\text { mesh, respectively............ }\end{array}$ & 55.85 & 29.42 & 14.75 \\
\hline
\end{tabular}

In the case of cellulose obtained from the hydrolyzed wood, considerable difficulty was encountered, owing to its character after treatment with the alkali. In all cases it was impossible to filter in the $30 \mathrm{~min}$. prescribed by the method, so that the action of the alkali continued in some cases for 8 or ro hrs. This difficulty could not be overcome, and no definite analysis could be made. The cellulose, upon treatment with alkali ( 7.5 per cent), became semitransparent and had the appearance of collodion.

That portion that could be drawn through the crucible reprecipitated upon mild dilution with water. This precipitate coagulated upon warming, and it behaved and looked very much like the usual $\beta$ cellulose. The coagulated precipitate was filtered on an alundum crucible with suction, and the filtrate acidified with strong acetic acid, with the result that no further precipitate was obtained. Because of the diffictulties outlined above, no analytical data on the $\alpha-, \beta$-, and $\gamma$-cellulose from the cellulose from hydrolyzed wood are contained in this paper. It is hoped that further investigations will clarify this point.

In one case the alkali-treated cellulose from hydrolyzed wood was strongly diluted with water. The fine white precipitate was warmed, and the coagulated material filtered, washed, and dried. It had the semitransparent appearance of dried collodion and amounted to 96 per cent of the original sample. Because of its peculiar properties it is apparently a product intermediate between $\alpha$ - and $\beta$-cellulose. Since it is partially soluble in alkali it may be concluded that it is more easily digested in the alkaline intestinal tract than the true $\alpha$-cellulose, especially in the presence of enzymes present in the intestines.

\section{METHOD FOR CRUDE FIBER DETERMINATION}

The crude fiber was determined by the method outlined in Bureat of Chemistry Bulletin 107, page 56, with minor modifications. It is briefly as follows:

Two grams of the sample are extracted with ether for 4 or $5 \mathrm{hrs}$. in a Soxhlet extractor. The excess of ether is removed by suction and the material dried to constant weight. It is then treated with $200 \mathrm{cc}$. of boiling I.25 per cent sulfuric acid, and boiled under a reflux condenser for 30 min. After filtering with suction on an alundum crucible it is washed with hot water and treated with $200 \mathrm{cc}$. of boiling I.25 per cent sodium hydroxide solution. After boiling for another $30 \mathrm{~min}$. under a reflux condenser it is rapidly filtered with suction through an alundum crucible and washed with hot water until free from alkali. After drying to constant weight it is incinerated in an electric muffle at $700^{\circ}$ to $800^{\circ} \mathrm{C}$. The loss on incineration is considered to be crude fiber.
It is interesting to note that the crude fiber has been reduced from I 4 to I 5 per cent. Another interesting feature is the fact that the sum of the cellulose and lignin is greater than the quantity of crude fiber. This indicates that at least a portion of either the cellulose or lignin, or perhaps some of each, is removed by successive treatments with dilute acid and alkali.

\section{SUMMARY}

I-A method for the preparation of a stock food from white pine sawdust is described.

2-Leaching experiments carried out on the digested dust indicate that five complete washings with a quantity of water equivalent to the weight of the wood are necessary to remove the sulfuric acid. The sugars were found to leach with somewhat more difficulty than the acid.

3-It is pointed out that the sugars contained in the moist product are not appreciably affected by drying at temperatures ranging from $75^{\circ}$ to $85^{\circ} \mathrm{C}$. While some decrease is noted in total reducing sugars, the loss is apparently due to the removal of volatile reducing stubstances.

4-A complete analysis is given for eastern white pine sawdust, and for the product obtained from the same after digesting with dilute acid under pressure. Attention is directed to the changes resulting from this treatment.

5-The cellulose obtained from the digested wood differs from that from the original wood in its behavior toward alkali. In the former practically all of the cellulose is converted into a viscous semitransparent mass by 17.5 per cent sodium hydroxide, while in the latter over 50 per cent is unaffected.

\section{THE EFFECT OF CONCENTRATION OF CHROME LIQUOR. UPON THE ADSORPTION OF ITS CONSTITUENTS BY HIDE SUBSTANCE ${ }^{1}$}

\section{By Arthur W. Thomas and Margaret W. Kelly}

Chimical Laboratories, Columbia UNIVERstTy, New York, N. Y.

The concentration factor in the combination of hide substance with chromic oxide and sulfuric acid in chrome liquor has previously been reported by Miss M. E. Baldwin. ${ }^{2}$ She studied the adsorption from various liquors containing 0.038 to $6.640 \mathrm{~g}$. of chromic oxide per Ioo cc. of liquor, and found that the adsorption reached a maximum at concentrations of $\mathrm{I} .5$ to $2.0 \mathrm{~g}$. of chromic oxide per $100 \mathrm{cc}$., beyond which concentration the adsorption by the hide substance decreased.

Results obtained by J. A. Wilson and E. A. Gallun ${ }^{3}$ in their investigation of the retardation of chrome tanning by neutral salts, led them to believe that, had Miss Baldwin's liquors been carried to higher concentrations (to about I $2 \mathrm{~g}$. of chromic oxide per Ioo cc.), a minimum point might have been obtained beyond which increasing concentration would have caused

1 Presented before the Leather Chemistry Division at the 60th Meeting of the American Chemical Society, Chicago, I11., September 6 to 10, 1920 .

$2 J$. Am. Leather Chem. Assoc, 14 (1919), 433

s Ibid., $15(1920), 273$. 
greater fixation of chrome. The experiments reported in this paper were conducted to test this assumption.

\section{MATERIALS USED}

The hide powder was American Standard (I9I8) of the same lot as used and analyzed by us. ${ }^{1}$

The chrome liquor contained $202 \mathrm{~g}$. of chromic oxide per liter. It was practically identical to that used by Miss Baldwin. Eleven 200-cc. portions of chrome liquor of various dilutions were made up from this stock liquor.

\section{METHOD}

The various diluted liquors in 200-cc. portions were poured into bottles containing $5.766 \mathrm{~g}$. of hide powder, equal to $5 \mathrm{~g}$. of dry hide powder. Another portion of each solution was set aside and at the expiration of 48 hrs. the $\mathrm{H}^{+}$-ion concentration of the solutions was determined. The bottles were shaken at intervals, and at the end of $48 \mathrm{hrs}$. filtered off by suction. The filtrates were set aside for analysis (the $\mathrm{H}^{+}$-ion concentrations determined immediately), and the chromed hide powders, washed free of adhering liquor, were air-cried. The methods of analysis were the same as those reported by us in our earlier communications.

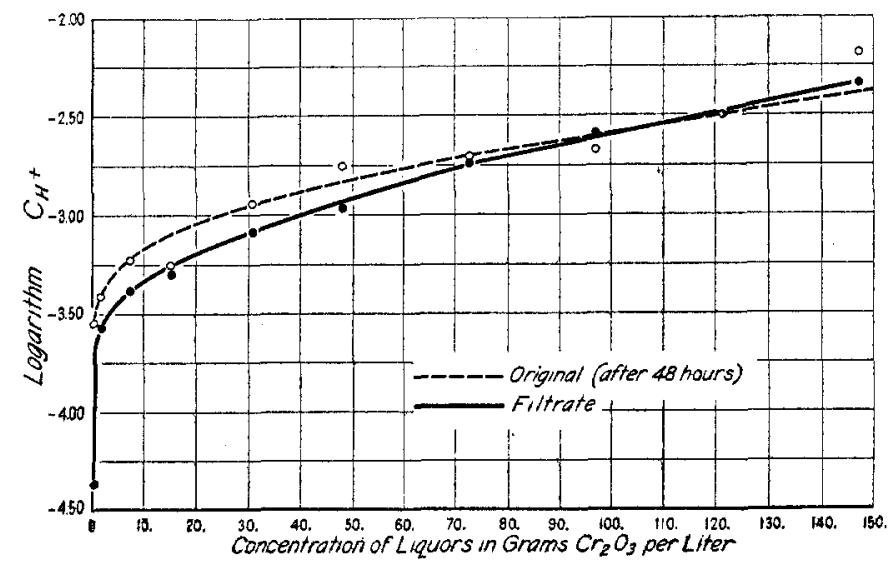

FIG. 1

The moisture was determined in each portion of the chromed hide powders and all other figures calculated to the water-free basis. The results are given in Table I.

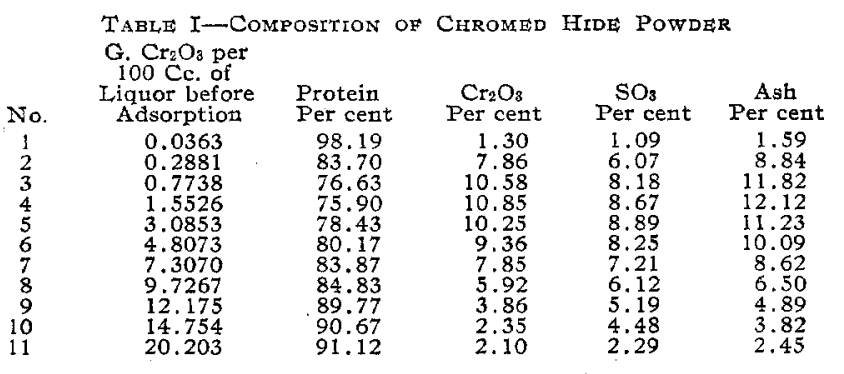

The analyses of the filtrates are given in Table II. An aliquot part was taken in each case, the chromic oxide in it determined and calculated to the basis of Ioo cc. of liquor, assuming, erroneously, that no water had been adsorbed by the hide-the common practice in calculations of adsorption.

I. Am. Leather Chem. Assoc., 15 (1920), 487 .

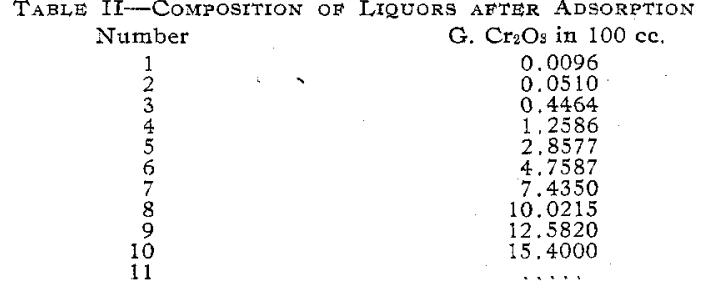

The $\mathrm{H}^{+}$-ion concentrations of the filtrates and of the liquors (after 48 hrs:' standing) are to be found in Table III and charted in Fig. I. Those values which are considered unreliable are in parentheses. In some of the concentrated liquors we had diffculty in measuring the $\mathrm{H}^{+}$-ion concentrations. The values obtained show removal of hydrogen ion from the liquors up to the solution of concentration of $7.4 \mathrm{~g}$. chromic oxide per roo cc., beyond which the curves join and run along together, indicating that if hydrogen ion was removed the buffer action of the chromic sulfate could take care of it. The solution which gave the maximum adsorption of chrome in two days showed a $\mathrm{H}^{+}$-ion concentration of 0.00056 mole per liter, which checks Miss Baldwin's experience, where the maximum adsorption of chrome in two days was found to be from a solution of 0.0005 to 0.0006 mole per liter concentration of hydrogen ion.

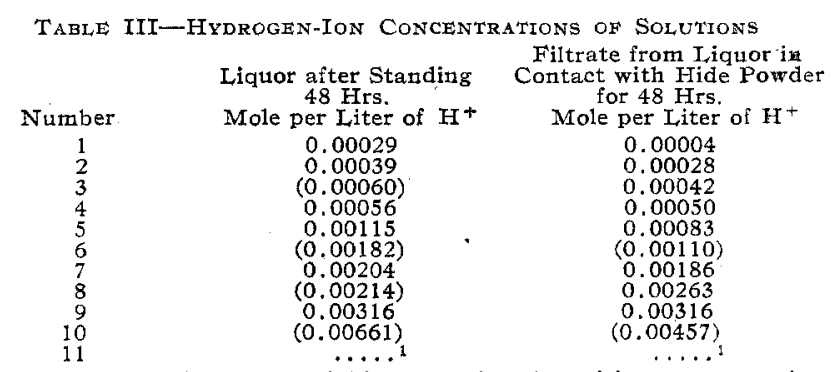

1 We have not been successful in measuring the $\mathrm{H}^{+}$-ion concentrations in such strong liquors.

Table IV and Fig. 2 show the adsorption of chromic oxide and sulfuric acid calculated to the basis of one gram of dry hide substance.

Tabie IV-Amounts OF Chromic OXide and Sulfuric Acrd Adsorbe

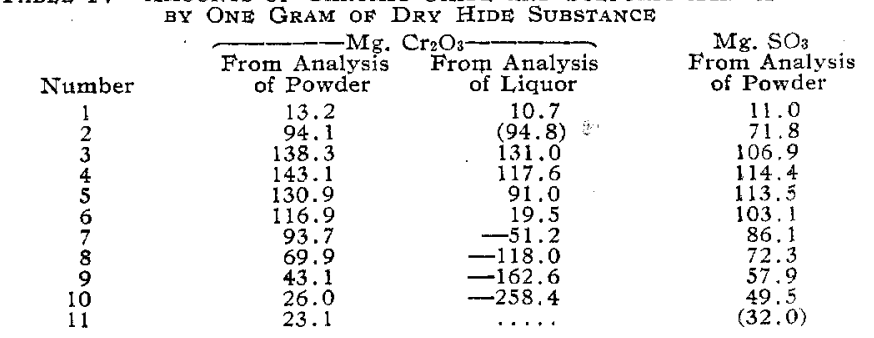

Solutions 3 and 4 showed the optimum concentration for a 2-day reaction with hide powder. The chromed hide substance formed indicates a tetrachrome collagen, based on the equivalent weight of collagen as 750 , as suggested by Wilson. ${ }^{1}$ This again checks Miss Baldwin's results quite closely.

The values based on analysis of the liquors, from which the adsorption of water was ignored, show lower values throughout, and from Solutions 7 to I I

'J. A m. Leather Chem. Assoc., 12 (1917), 108. 
negative values are obtained, owing to the liquors becoming more concentrated than they were originally, on account of the collagen abstracting water from them.

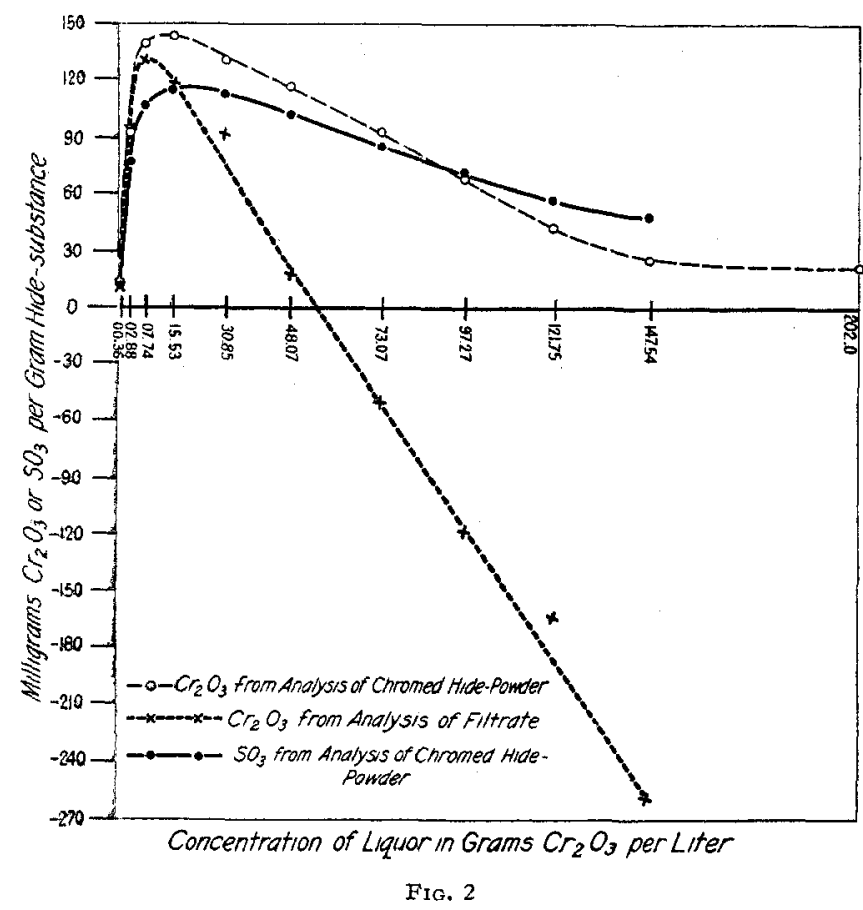

We would state our belief, based upon our experience as presented in this and earlier papers, that the reaction between chromic sulfate solutions and hide substance is chemical and not physical, as contended by A. W. Davison. ${ }^{1}$ If the adsorption were a simple physical process, $i$. e., merely a partition of the chromic oxide and sulfuric acid between the solid hide substance phase and the solution phase, the curve should follow Freundlich's adaptation of Henry's law: $\mathrm{C}_{1}=k \mathrm{C}_{2}{ }^{n}$, which is parabolic in shape; whereas Miss Baldwin's and our experiments show that in a 2 -day adsorption the curve begins to slope steeply downward after the concentration of the liquor exceeds approximately r $6 \mathrm{~g}$. of chromic oxide per liter in a solution of the composition of $\mathrm{Cr}(\mathrm{OH}) \mathrm{SO}_{4}$, and reaches a minimum when the concentration of chromic oxide is $147.5 \mathrm{~g}$. per liter, this minimum being maintained at a concentration of $202 \mathrm{~g}$. per liter. This minimum confirms the prediction of Wilson and Gallun in part. The most concentrated chrome liquor which we used was very thick and about as concentrated as is possible to handle; and therefore, we do not find it possible to test further their prediction that increasing concentrations beyond this minimum would cause greater fixation of chrome.

\section{ACKNOWLEDGMENTS}

Acknowledgment is made of Mr. S. B. Foster's assistance in the analytical work. We wish to express our great appreciation of the generous support of Messrs. A. F. Gallun and Sons Company in this investigation.

: J. Am. Leather Chem. Assoc., 12 (1917), 258

\section{THE ACTION OF CERTAIN ORGANIC ACCELERATORS JN THE VULCANIZATION OF RUBBER-II ${ }^{1}$}

\section{By G. D. Kratz, A. H. Flower and B. J. Shapiro}

The Falis Rubare Co., Cuyahoga Falls, Ohio

One of the early patents ${ }^{2}$ for the use of synthetic nitrogenous organic substances in the vulcanization of rubber refers to the dissociation constant of $\mathrm{I} \times 10^{-8}$ as the dividing line between accelerating and nonaccelerating bases. On the other hand, Peachey ${ }^{3}$ has pointed out that certain other substances which are not basic, or but slightly so, are also exceedingly active as accelerators. The number of examples in this class, however, is relatively small.

In the course of the experimental work described in. this paper we have made a comparison of the sulfur coefficients of a type mixture vulcanized with the assistarice of a number of accelerators closely related to aniline and for which the dissociation constants are known. We have also employed the hydrochlorides of two of these substances, relatively weak and strong bases, in order to observe the effect of the acid portion during the vulcanization. The results obtained and the conclusions drawn led us to employ the sulfides of ammonia as accelerators and vulcanizing agents.

Briefly summarizing these results, it was found that with the substances tested there was apparently no direct relationship between their dissociation constants and their excess sulfur coefficients or physical properties after vulcanization. In a closely related series, such as aniline and its methyl derivatives, the substance with the largest dissociation constant was found to be the most active. However, the relative activities of the members of this series were not proportional to their dissociation constants. Generally speaking, the activity of all of the substances could be traced to the amino group, and depended to a large extent upon whether or not substitution had taken place in this group. In this respect, they should probably be regarded as substituted ammonias, rather than as the more complex derivatives of other substances.

One effect of the basicity of two of the substances, methylaniline and $p$-toluidine, was determined with the hydrochlorides of these two substances. Our results showed that with substances of this type, the first effect of the base is to neutralize the retarding action of the acid formed in the decomposition of the salt during vulcanization. We had previously suggested this in a footnote in a former paper. ${ }^{4}$ We also found that when the acid liberated in the decomposition of such a salt is neutralized by other substances in the mixture, the activity of the hydrochloride is very close to that of the free base. These results are of particular interest, as Van Heurn ${ }^{5}$ has shown that, whereas ammonium carbonate is moderately active as an accelerator in a mixture of rubber and sulfur,

1 Presented before the Rubber Division at the 60th Meeting of the American Chemical Society, Chicago, Ill., September 6 to 10,1920 .

D. R. P. 280,198 (1914)

3 J. Soc, Chem. Ind., 36 (1917), 950

- Chem. \& Met. Eng., 20 (1919), 420.

s Comm. of the Netherlands Government for Advising the Rubber Trade and Industry, Part 6, 202 